\title{
Characterizing larval swordfish habitat in the western tropical North Atlantic
}

Running title: Characterizing larval swordfish habitat

JUSTIN J. SUCA ${ }^{1,2^{*}}$, LEIF K. RASMUSON ${ }^{1,3,4}$, ESTRELLA MALCA ${ }^{1,3}$, TRIKA GERARD ${ }^{3,5}$, JOHN T. LAMKIN ${ }^{3}$

1. Cooperative Institute of Marine and Atmospheric Studies, University of Miami, 4600 Rickenbacker Causeway, Miami, FL, 33149

2. Biology Department, Woods Hole Oceanographic Institution, 266 Woods Hole Rd MS\#33, Woods Hole, MA, 02543

3. Southeast Fisheries Science Center, NOAA National Marine Fisheries Service, 75 Virginia Beach Drive, Miami, FL 33149, USA

4. Marine Resources Program, Oregon Department of Fish and Wildlife, 2040 SE Marine Science Drive, Newport, Oregon 97376, USA

5. University of Phoenix, South Florida Campus, 2400 SW 145 Ave, Miramar, FL 33027, USA

*Email: jsuca@whoi.edu 


\begin{abstract}
:
Swordfish Xiphias gladius (Linnaeus, 1758) are a circumglobal pelagic fish targeted by multiple lucrative fisheries. Determining the distribution of swordfish larvae is important for indicating reproductive activity and understanding the early life history of swordfish. We identify and characterize larval swordfish distributions during peak swordfish spawning throughout the Gulf of Mexico and western Caribbean Sea with generalized additive models (GAMs) using catches of swordfish larvae during ichthyoplankton surveys in April and May of 2010, 2011, and 2012. The best fit GAM, as determined by stepwise, backward Akaike Information Criterion selection, included both physiochemical (temperature at $5 \mathrm{~m}$, sea surface height anomaly (SSHA), eddy kinetic energy (EKE)), temporal (lunar illumination, hour of sampling) and spatial (location) variables, while near-surface chlorophyll $a$ concentration residuals remained as a random effect. The highest probability of larval swordfish catch occurred at sub-surface temperatures, SSHA, and EKE values indicative of boundary currents. Standard lengths of larvae were larger further downstream in the boundary currents, despite high variability in length with location due to multiple spawning locations of swordfish near these currents. Probability of larval swordfish catch also peaked during the crescent and gibbous moons, indicating a lunar periodicity to swordfish spawning. These results suggest that swordfish may spawn during select moon phases near boundary currents that transport their larvae to larval and juvenile habitat including the northern Gulf of Mexico and coastal waters of the southeast United States.

Key Words: GAM, Larval Habitat, Gulf of Mexico, Caribbean Sea, Xiphiidae, Swordfish
\end{abstract}


2

3

4

5

6
7

8

10

11

12

13

14

15

16

17

18

19

20

21

22

23

24

25

26

27

28

29

30

31

32

33

34

35

36

37

38

39

40

41

42

43

44

45

46

47

48

49

50

51

52

53

54

55

56

57

58

59

60 


\section{INTRODUCTION:}

Swordfish Xiphias gladius (Linnaeus, 1758) are a circumglobal oceanic fish targeted by multi-million-dollar longline and drift gill net fisheries (Ito et al., 1998; Ward et al., 2000). Swordfish caught in the United States Atlantic Exclusive Economic Zone (EEZ) are primarily members of the Northwest Atlantic stock as defined by the International Commission for the Conservation of Atlantic Tunas (ICCAT, 2014). Swordfish in this stock migrate from the Grand Banks off Newfoundland to the Caribbean Sea and Gulf of Mexico (Palko et al., 1981; Nakamura, 1985; Neilson et al., 2014). Juvenile swordfish $(<130 \mathrm{~cm})$ prefer warmer waters such as the Gulf of Mexico and waters of the southeast US, while larger swordfish primarily occupy waters with colder surface temperatures, such as Georges Bank (Muhling et al., 2015).

In addition to large scale geographical migrations, adult swordfish are vertical migrators, spending nights near the surface and diving to depths of $\sim 900 \mathrm{~m}$ during daylight (Takahashi et al., 2003; Abascal et al., 2010). This behavior matches the similar vertical migration of their prey items: squid and mesopelagic fishes (Scott and Tibbo, 1968; Chancollon et al., 2006). Further, the extent of vertical migration is influenced by the lunar phase with swordfish ascending to shallower (deeper) depths in low (high) lunar illumination (Lerner et al., 2013).

Northwest Atlantic swordfish populations spawn year-round in the Atlantic, from Cape Hatteras to the waters North of Puerto Rico (see Fig. 1), including the Caribbean Sea and Gulf of Mexico (Arata, 1954; Grall et al., 1983; Govoni et al., 2000; 2003; Bremer et al., 2005). Most spawning occurs between December and June in the Gulf of Mexico and Caribbean (Taylor and Murphy, 1992; Arocha, 1997; Govoni et al., 2003). The neustonic eggs of swordfish spawned in the Caribbean Sea (where average temperatures are $\sim 25^{\circ} \mathrm{C}$ ) take approximately three days to hatch (Yasuda et al., 1978; Enfield and Mayer, 1997). After hatching, pre-flexion swordfish larvae occupy the upper $10 \mathrm{~m}$ of the water column, exclusively consuming copepods (Govoni et 
25 al., 2003). Swordfish larvae become neustonic and piscivorous at approximately two weeks of 26 age, corresponding to notochord flexion (Govoni et al., 2003).

Swordfish larvae of various sizes have been found throughout the western Atlantic and

28 Caribbean, resulting in uncertainty in their spawning locations. Grall et al. (1983) observed small

29 larvae $(<10 \mathrm{~mm})$ in the eastern Caribbean and Straits of Florida and larger larvae $(>10 \mathrm{~mm})$ near

30 the western Antilles. Govoni et al., (2000) suggested that larvae may be spawned as far north as

31 Cape Hatteras. Further, estimations of spawning locations for swordfish larvae caught in the Gulf

32 of Mexico and Caribbean have ranged from the north central Gulf of Mexico to the eastern

33 Caribbean, suggesting spawning may occur as far south as the southern extent of the Sargasso

34 Sea and the beginning of the Caribbean Current (Govoni et al., 2003). Distribution and larval

35 habitat have also been described for swordfish larvae in the north central Gulf of Mexico,

36 suggesting that spawning may occur within the Gulf of Mexico (Rooker et al., 2012). However,

37 the spatial and temporal extent of many of these studies were limited, with either a limited intra-

38 seasonal spatial extent or spatially limited to regions in the Gulf of Mexico or southeastern

39 United States (Govoni et al., 2000; Rooker et al., 2012).

40 Surface transport in the Gulf of Mexico and western Caribbean Sea is dominated by the

41 Caribbean, Yucatan, and Loop Currents, which become the Florida Current and ultimately the

42 Gulf Stream after passing through the Straits of Florida (Fig. 1; Oey et al., 2005). The Caribbean

43 and Loop Currents flow over large zonal distances ( $\geq 400 \mathrm{~km}$ in the case of the Loop Current),

44 permitting meanders that can separate from the dominant current in the form of mesoscale eddies

45 (Candela et al., 2002; Richardson, 2005). The Yucatan Current, however, passes through a

46 topographically constrained channel, resulting in minimal eddy shedding and less variability in

47 its zonal extent (Oey et al., 2005; Carillo et al., 2016). The fronts associated with boundaries of 
48 the current systems, as well as the anticyclonic mesoscale eddies they shed, create convergence

49 zones that concentrate plankton and form essential habitat for pelagic organisms (Bakun, 1996;

50 2006). These convergent zones in the Gulf of Mexico and Caribbean Sea are often used for

51 spawning and larval habitat by large pelagic fishes such as Atlantic bluefin tuna Thunnus thynnus

52 (Linnaeus, 1758) and sailfish Istiophorus platypterus (Shaw, 1792; Teo et al., 2007; Richardson

53 et al., 2009; Muhling et al., 2010; Simms et al., 2010). Areas of convergence, such as the Gulf

54 Stream front, serve as habitats for pre-flexion larvae because due to their ability to concentrate

55 larval swordfish (Govoni et al., 2000). Rooker et al., (2012) also showed that the greatest

56 probabilities of larval swordfish catches are associated with the Loop Current boundary, further

57 suggesting that fronts may serve as larval swordfish habitat.

58 Data from ichthyoplankton surveys along with oceanographic parameters can begin to

59 elucidate seasonal patterns of larval fish distributions (Houde et al., 1979; Hernandez et al.,

60 2010; Muhling et al., 2010; 2012; Domingues et al., 2016). Habitat models can be formed using

61 catch data and bio-physical data collected during surveys to predict larval fish distributions to

62 better understand the diversity and abundance of these larvae in the pelagic environment (Rooker

63 et al., 2012). The purpose of this work was to identify and predict larval swordfish distributions

64 during the months of April and May, encompassing part of the peak spawning for swordfish

65 throughout the Gulf of Mexico and western Caribbean Sea (Govoni et al., 2003). This provides

66 an opportunity to assess the distribution of swordfish in this region during the same season for

67 three consecutive years, significantly improving our current understanding of larval swordfish

68 distribution and swordfish spawning. Based on observations of swordfish larvae in the Gulf of

69 Mexico and Caribbean, we hypothesized that larvae will most likely to be found in the

70 Caribbean, Yucatan, and Loop Currents which may serve to transport larvae to suitable habitat to 
71 optimize growth and/or survival. This work assesses this hypothesis through formation of habitat

72 models to improve our understanding of the life history of swordfish and further predicts

73 spawning locations based on the size of larvae collected.

74

75 METHODS:

76 Data collected during the 2010-2012 Southeast Area Monitoring and Assessment

77 Program (SEAMAP) Spring Ichthyoplankton Surveys were used to determine how

78 oceanographic features influence the presence/absence of swordfish larvae. Sampling occurred

79 during the months of April and May in the western Gulf of Mexico, the edge of the Loop

80 Current, and the Yucatan Channel. Western Caribbean sampling regions varied by year (Fig. 2).

81 Plankton tows were conducted at each station undulating a $1 \times 2 \mathrm{~m} 0.505 \mathrm{~mm}$ mesh net fitted with

82 a flowmeter (2030R, General Oceanics, Inc) between the surface and $10 \mathrm{~m}$ depth for 10 minutes

83 (hereafter referred to as S-10; Habtes et al., 2014). Additional neuston tows were also conducted

84 for $10 \mathrm{~min}$ at various stations using a 1 x $2 \mathrm{~m} 0.947 \mathrm{~mm}$ mesh net. Tows were conducted during

85 both day and night. Volume filtered for each tow $\left(\mathrm{m}^{3}\right)$ was calculated from flowmeter counts. At

86 most stations a Seabird SBE 9/11 Plus CTD (conductivity, temperature, and depth) equipped

87 with a dissolved oxygen sensor (SBE 43) was deployed to $300 \mathrm{~m}$. CTD casts were restricted to

$8850 \mathrm{~m}$ above the bottom for stations shallower than $350 \mathrm{~m}$.

89 Data Processing/Physical Variables:

90 Swordfish larvae were identified using morphological characteristics by the Sea Fisheries

91 Institute, Plankton Sorting and Identification Center in Szczecin, Poland. Body length was

92 measured as standard length (SL) or notochord length (NL) to the nearest $0.05 \mathrm{~mm}$ (Supp. Table

93 1). Maps of the presence/absence and SL of swordfish larvae for each cruise were generated 
94 using Esri ArcGIS system (Desktop 10.4.1). Sea surface temperature data from the Hybrid 95 Coordinate Ocean Model (HYCOM) $1 / 12^{\circ}$ resolution Global Reanalysis

96 (http://hycom.org/data/glbu0pt08/expt-19pt1) were interpolated using the Marine Geospatial 97 Ecology Toolbox across the sampling region (Roberts et al., 2010). Physicochemical parameters were obtained from in-situ CTD data, satellite data, and 99 HYCOM for use in habitat model formation. Values for daily average sea surface height 100 anomaly and current velocity were obtained for each station using HYCOM estimates. Eddy 101 kinetic energy was calculated from these current velocities using the formula:

102

103 104 105 106 107 108 109 110 111 112 113 illumination for each sample day was obtained from the US Navy database

\section{4 (http://aa.usno.navy.mil/data/docs/MoonFraction.php).}

Physicochemical parameters considered in model development were: temperature $\left({ }^{\circ} \mathrm{C}\right)$ at

$1165 \mathrm{~m}$, temperature $\left({ }^{\circ} \mathrm{C}\right)$ at $100 \mathrm{~m}$, near-surface chlorophyll $a$ concentration residuals calculated by 
117 removing the temperature trend $\left(\mathrm{mg} \mathrm{m}^{-3}\right)$, dissolved oxygen $(5 \mathrm{~m})$ residuals calculated by 118 removing the temperature trend $\left(\mathrm{mg} \mathrm{L}^{-1}\right)$, salinity $(5 \mathrm{~m})$, year, hour of day, latitude, longitude, 119 fraction of lunar illumination, depth (m), eddy kinetic energy $\left(\mathrm{m}^{2} \mathrm{~s}^{-2}\right)$, sea surface height 120 anomaly (m), sea surface height anomaly gradient, and eddy kinetic energy gradient (Table 1).

121 This suite of variables was chosen because they can be used to differentiate and characterize 122 oceanographic features in the sampling region. Volume of water filtered $\left(\mathrm{m}^{3}\right)$, hereafter volume 123 filtered by the net was log transformed for each station and included to standardize sampling 124 effort because of positive skew in the volume filtered values. All in situ variables (temperature, 125 dissolved oxygen, and salinity) were determined as the value closest to the desired depth (5 m or $126100 \mathrm{~m}$ ) from the CTD downcast. Residuals of a linear regression with temperature of both 127 dissolved oxygen and chlorophyll $a$ were used because oxygen and chlorophyll $a$ were strongly 128 collinear with temperature $(r=-0.74, p<0.01 ; r=-0.49, p<0.01 ;$ Fig. 3$)$. The temperature trend was 129 removed because it drives patterns of both dissolved oxygen and chlorophyll $a$ (Garcia and 130 Gordon, 1992; Feng et al., 2015). Gradient of sea surface height anomaly and gradient of eddy 131 kinetic energy were calculated as the gradient between the two nearest HYCOM values $\left(1 / 12^{\circ}\right.$ 132 separation) to each station for the day of sampling.

133 Stations lacking CTD casts or containing errors in oxygen values due to sensor 134 malfunction were removed. In addition, stations sampled in continental shelf waters $(<200 \mathrm{~m}$ 135 depth) were removed prior to model formation ( $\mathrm{n}=117$ stations removed in total). This is due to 136 high hydrographic variability in coastal waters (thus the poor accuracy of HYCOM in these 137 regions) and previous studies suggesting that swordfish larvae are rare in depths $<200 \mathrm{~m}$ (Grall 138 et al., 1983; Chassignet et al., 2007).

139 Model Formation: 
The aforementioned variables were used to develop generalized additive models (GAMs)

141 in order to explore the effects of the physical environment on the distribution of swordfish larvae

142 (Hastie and Tibshirani, 1990). GAMs are statistical models that allow a combination of

143 physicochemical parameters to interact in a non-linear manner with the response variable and are

144 non-linear extensions of generalized linear models (Barry and Welsh, 2002). These models

145 provide a means to discover larval habitats that are difficult to identify through linear models and 146 simple correlations.

147 GAMs for this project were developed using the $m g c v$ library in R statistical software

148 (Version 3.2.3) (Wood, 2008; 2017). We developed presence/absence models rather than

149 abundance (e.g. catch per unit effort) since abundance data for ichthyoplankton can be difficult

150 to assess due to the patchy distribution of fish larvae and the course spatial scale of sampling.

151 The response variable for all models was the presence/absence of swordfish in the S-10 tows as

152 these were conducted at each station and showed a higher frequency of swordfish catch than the

153 neuston net. All predictor variables were tested for covariance and collinearity using a

154 correlation matrix followed by plotting and calculating Pearson's product-moment correlation

155 coefficients $(r)$ for each set of covariates. Correlation of predictor variables to the response

156 variable were then analyzed through single variable GAMs. The predictor variable showing

157 largest deviance explained when plotted against the response variable was selected for use in the

158 model. Models were developed using a binomial distribution with a logit link function. Smooth

159 functions related the response variable (larval presence/absence) to the model parameters,

160 permitting non-linear relationships. Each smoothing function was permitted three degrees of

161 freedom to minimize overfitting with the exception of fraction of lunar illumination, which was

162 permitted five (Sunbland et al., 2009; Rooker et al., 2012). Five degrees of freedom permits the 
163 fraction of lunar illumination to incorporate sinusoidal and bimodal responses. Response curves 164 provided visual representations of the smooth functions to qualitatively relate patterns of 165 presence/absence to physicochemical parameters.

166 Three parameters were removed due to collinearity: temperature at $100 \mathrm{~m}$ (collinear with 167 temperature at $5 \mathrm{~m}, \mathrm{r}=0.62$ ), EKE gradient (collinear with temperature at $5 \mathrm{~m}, \mathrm{r}=-0.45$ ), and sea 168 surface height anomaly gradient (collinear with EKE, $\mathrm{r}=0.55$ ). After removal of these variables, 169 the base model included eleven predictor variables and was developed using the following 170 equation:

171 [2] Swordfish presence $=\operatorname{offset}(\log ($ Volume filtered $))+\mathrm{s}($ Temperature at $5 \mathrm{~m})+\mathrm{s}($ Oxygen 172 residuals $)+\mathrm{s}($ Chlorophyll- $a$ residuals $)+\mathrm{s}($ Salinity at $5 \mathrm{~m})+\mathrm{s}($ Fraction of Lunar Illumination $)+$ $173 \mathrm{~s}($ Depth $)+\mathrm{s}($ Sea Surface Height $)+\mathrm{s}($ Eddy Kinetic Energy $)+$ te(Longitude,Latitude $)+\mathrm{s}($ Hour of 174 Sampling)+Year

175 Where s represents a smooth function and te represents a tensor spline, which allows longitude 176 and latitude to interact anisotropically (Zurr, 2012; Wood, 2017).

177 A stepwise backwards Akaike Information Criterion (AIC) method was used to select the 178 best fit model. AIC is calculated using the following formula

182 where $l$ is the maximized $\log$ likelihood and $K$ is the number of estimable parameters (Burnham 183 and Anderson, 2002). The model that resulted in the lowest AIC was selected for each iteration 184 with the exception of situations where the response curves did not permit reasonable ecological 185 inference. Model selection was further verified by examining the Akaike weights for each 
186 iteration of models to select the best model. Akaike weights are calculated through the following 187 equation:

188

$$
\text { [4] } w_{i}=\frac{\exp \left[-\frac{1}{2} \Delta_{i}\right]}{\sum_{i=0}^{n} \exp \left[-\frac{1}{2} \Delta_{i}\right]}
$$

189 Where $\Delta_{\mathrm{i}}$ represents the difference in AIC of a particular model from the lowest AIC for any 190 model in that iteration. Akaike weights can be interpreted as the probability that a model is the 191 best model for the iteration (Burnham and Anderson, 2002).

192 Once a best-fit model was determined, bootstrapping was used to make a Receiver 193 Operating Characteristic (ROC) curve and measure the area under that curve (AUC). A randomly 194 selected subset of 120 stations was used as a training data set (approximately one quarter of the 195 data) with the remaining data serving as the test data set (Huberty, 1994). The true positive rate 196 of the bootstrap simulation was plotted against the false positive rate to create a ROC curve. The 197 integration of this curve results in an AUC value. AUC values close to one represent a good fit of 198 the model to the data set, with values exceeding 0.90 considered excellent. This bootstrapping 199 was repeated 1000 times and the mean, median, and standard deviation of these AUC scores 200 were calculated.

201

202 RESULTS:

203 One hundred and ninety-seven swordfish larvae were collected from S-10 and neuston 204 nets over the three years of sampling with 78 of $603(12.96 \%)$ stations sampled positive for 205 presence of swordfish larvae (Fig. 2). Mapping of swordfish catch with monthly mean sea 206 surface temperature showed a clear association of swordfish larvae with the waters of Caribbean 207 Current, Yucatan Current, and Loop Current. The only exceptions were in two stations 
208 containing swordfish larvae near the continental rise of the northwest Gulf of Mexico in 2012 209 (Fig. 2c)

210 Larger swordfish larvae $(>6.5 \mathrm{~mm})$ were also generally caught in the Loop Current with 211 small individuals $(<6.5 \mathrm{~mm})$ being more present near the Yucatan and Caribbean Currents (Fig. 212 4). The exception was 2012 which showed small larvae near the southeastern extent of the Loop 213 Current as it becomes the Florida Current. There were also three stations containing large 214 swordfish larvae near Hispaniola in 2011. No significant correlation with latitude and standard 215 length of swordfish was found $(\mathrm{r}=0.05, \mathrm{p}=0.63)$. Smaller individuals were also present in the 216 northern and western Loop Current in 2010 and 2011 while eastern extent of the Loop Current 217 primarily contained larger larvae in these years.

218 Model:

219 Four hundred and eighty-six stations remained (62 stations containing swordfish larvae) 220 after oxygen outliers, stations without CTD casts, and shelf waters were removed from the 221 dataset for model formation (Fig. 2).

222 Seven variables remained in the model after a backwards step-wise AIC model selection: 223 temperature at $5 \mathrm{~m}, \mathrm{SSHA}, \mathrm{EKE}$, fraction of lunar illumination, hour of sampling (local time), 224 and an interaction between latitude and longitude (Table 2). Chlorophyll $a$ residuals were also 225 included as a random effect in the model as they reduced residual heterogeneity (Zurr et al., 226 2009). This was because the smooth function of chlorophyll $a$ residuals was not significant in the 227 model, but did show collinearity when plotted against residuals of a GAM that did not include 228 chlorophyll $a$ residuals.

229 The final AIC for this model was 290.542 and the total deviance explained (DE) was $23033.1 \%$ (Table 3 ). The variables in order of greatest $\triangle \mathrm{AIC}$ were longitude and latitude $(\Delta \mathrm{AIC}$ 
$231=19.02, \Delta \mathrm{DE}=6.3 \%)$, percent lunar illumination $(\Delta \mathrm{AIC}=17.91, \Delta \mathrm{DE}=7.7 \%)$, temperature at five 232 meters $(\triangle \mathrm{AIC}=13.65, \Delta \mathrm{DE}=9.7 \%)$, hour of sampling $(\triangle \mathrm{AIC}=9.58, \Delta \mathrm{DE}=2.0 \%)$, sea surface

233 height anomaly $(\triangle \mathrm{AIC}=8.10, \Delta \mathrm{DE}=1.9 \%)$ and eddy kinetic energy $(\triangle \mathrm{AIC}=2.98, \Delta \mathrm{DE}=0.1 \%)$.

234 The Akaike weight for the model selected in the final iteration was 0.780 , which was strongly

235 indicative of the best-fit model. The ROC curve for the final model indicated a strong predictive 236 capability of the model within the dataset. The average AUC for 1000 runs was 0.865 , a median 237 AUC of 0.866 , and a standard deviation of 0.047 .

$238 \quad$ Probability of swordfish presence increased as temperature increased from $24^{\circ} \mathrm{C}$ to $28^{\circ} \mathrm{C}$ 239 with highest catch at surface temperatures of $28^{\circ} \mathrm{C}$ (Fig. 5a). Probability of larval swordfish 240 catch reached a maximum around $0.17 \mathrm{~m}$ SSHA with a near parabolic curve showing lowest 241 probability around both low $(-0.4 \mathrm{~m})$ and high $(0.6 \mathrm{~m})$ SSHA (Fig. 5b). Probability of catch 242 decreased as eddy kinetic energy increased, though the magnitude of additive effect was minimal 243 (Fig. 5c). Fraction of lunar illumination displayed an uneven sinusoidal pattern with peak 244 probability of catch occurring prior to gibbous ( 0.75 illumination) and crescent (0.25 245 illumination) moons (Fig. 5d). Lowest probability of catch occurred during the quarter-moons 246 (0.5 illumination). The response curve for hour of collection was significant, but showed little 247 overall effect on probability of catch. Highest probability occurred between 1000-1500 local 248 time (Fig. 5e). No significant relationship or pattern between fraction of lunar illumination and 249 hour of sampling occurred, indicating that these parameters had independent effects on the catch 250 of swordfish larvae.

251

252 DISCUSSION: 
This study shows a clear association between the presence of larval swordfish and the

254 fast-moving currents in the western Caribbean Sea and Gulf of Mexico (Fig. 2). Our habitat

255 models corroborate these findings with the highest probabilities of catching larvae at

256 physicochemical values indicative of these current systems. Additionally, assessment of the

257 standard length of larvae by region corroborates findings from previous catches of larval

258 swordfish and mature adults that suggest there are likely multiple spawning locations south of

259 the Gulf of Mexico near the Caribbean Current and Yucatan Channel, with possible spawning

260 occurring in the northern and western extents of the Loop Current (Govoni et al., 2003; Arocha,

261 2007; Rooker et al., 2012). These concepts have been documented before but this study expands

262 our knowledge of the physicochemical parameters that constitute larval habitat throughout both

263 the Gulf of Mexico and Caribbean Sea, differentiates the oceanographic features likely used for

264 spawning by swordfish, indicates a connection between lunar illumination and swordfish

265 spawning, and documents new locations and abundances of swordfish larvae throughout the

266 western tropical North Atlantic.

267 The response curve for temperature at $5 \mathrm{~m}$ supports this hypothesis, showing a higher

268 additive effect with increasing temperature. This result suggests the presence of larvae in warm

269 waters, a characteristic of the Loop Current (Domingues et al., 2016). These values were

270 consistent with Rooker et al., (2012), which observed peak catch of swordfish larvae at

271 temperatures around $28^{\circ} \mathrm{C}$. However, their sampling occurred in the warmer months of June and

272 July in the north central Gulf of Mexico, likely leading to the negative relationship observed

273 between surface temperature and larval swordfish catch. The response curve for SSHA shows the

274 highest probability of catch around $0.17 \mathrm{~m}$, the same SSHA referenced as indicating the outer

275 Loop Current boundary (Fig. 5b). This supports the hypothesis that the Loop Current is used as 
276 larval habitat (Leben and Born, 1993; Berger et al., 1996; Hamilton et al., 2000; Leben et al., 277 2002). This is inconsistent with the findings of Rooker et al., (2012) which found larval 278 swordfish catch to be highest at negative sea surface height anomalies. However, in 2012 we 279 observed swordfish larvae in northcentral Gulf of Mexico waters in waters with a negative sea 280 surface height anomaly, yet near the Loop Current boundary (Fig. 6). Therefore, it is possible 281 that the increased probability of larval swordfish catch Rooker et al., (2012) observed in the 282 northern Gulf of Mexico is specific to this smaller region and is not consistent throughout the 283 larger spatial extent of larval swordfish habitat. Further, Rooker et al., (2012) did show a 284 negative relationship with distance from the Loop Current, suggesting that the Loop Current was 285 important larval swordfish habitat, corroborating our findings (2012). Eddy kinetic energy (EKE) 286 shows highest probability of catch, though minimal, near zero eddy kinetic energy (Fig. 5c). This 287 would be the case in a water mass that exhibits very little meridional or zonal flow such as 288 common water or fronts (Ducet and Le Traon, 2001). The fastest moving waters of boundary 289 currents and eddies display higher EKE values, suggesting these regions may not represent larval 290 swordfish habitat (Richardson, 2005). However, it is worth noting that the deviance explained by 291 EKE was low (0.1\%) and the significance of this parameter may have changed if we were able to 292 incorporate more stations into model formation near the Yucatan Channel in 2010 (Table 3; Fig. $2932)$.

294 An overview of our sampling and modeling indicate that swordfish do not rely heavily 295 on mesoscale eddies for spawning and larval habitat. Instead, swordfish larvae remain near and 296 within large current systems, a significant development in understanding larval swordfish 297 ecology. Mesoscale eddies were sampled during our collections and are common hydrographic 298 features in the Gulf of Mexico and Caribbean Sea (Hurlburt and Thompson, 1982; Vukovich and 
299 Maul, 1985; Carton and Chao, 1999). These eddies are often used for spawning and larval 300 transport of pelagic fishes, such as bluefin tuna and billfishes (Richardson et al., 2009; Govoni et 301 al., 2010; Muhling et al., 2010). Therefore, the use of large currents as opposed to mesoscale 302 eddies for spawning and larval habitat by swordfish represents a life history strategy unique from 303 other pelagic predatory fishes. These observed patterns of swordfish spawning near fast-moving 304 currents are similar to the spawning patterns of swordfish in the Mediterranean, where swordfish 305 spawn near areas with high current velocity such as the Straits of Messina (Megalofonou et al., 306 1995; Relini et al., 2003). This suggests that spawning near fast-moving currents is a strategy 307 that is not unique to the North Atlantic swordfish population.

308 The warm temperatures of boundary currents can lead to increased growth rates for fish 309 larvae, which is advantageous for outgrowing a larval stage with abundant predators (Bailey and 310 Houde, 1989; Houde, 1989). However, to sustain fast growth rates in warm waters, larvae need 311 ample prey. Boundaries associated with current systems represent convergence zones that 312 concentrate fish larvae and zooplankton, the prey of swordfish larvae (Bakun, 2006). Thus, 313 swordfish larvae may use the boundaries of major currents both for their warm waters and prey 314 abundance (Fig. 6). Specifically, the Loop Current boundary contains large numbers of Oithona 315 spp. copepods, a known prey item of pre-flexion swordfish larvae (Govoni et al., 2003;

316 Rathmell, 2007). The presence of neustonic flyingfish (Exocoetidae) and subsurface tuna and 317 mackerel (Scombridae) larvae may make these boundaries ideal habitat for swordfish larvae as 318 they transition to piscivory (Arata, 1954; Gorbunova, 1969; Richards et al., 1993; Govoni et al., 319 2003). However, convergence zones often lead to increased predation pressure and may increase 320 mortality of swordfish larvae, representing a trade-off between increased food availability and 321 predation (Bakun, 2006). 
Further, small larvae $(<6 \mathrm{~mm} \mathrm{SL})$ were primarily caught north of Honduras, in the

323 Yucatan Channel, and the northern and western extents of the Loop Current, with larger larvae

324 ( $>6 \mathrm{~mm} \mathrm{SL}$ ) occurring on the eastern side of the Loop Current (Fig. 4). However, there was a

325 great degree of variability in this trend, suggesting that there are multiple spawning locations

326 throughout the region including the near the Caribbean Current, Yucatan Channel, and the Gulf

327 of Mexico, corroborating suggestions of these spawning locations from previous studies

328 (Arocha, 1997; Govoni et al., 2003; Arocha, 2007). The general trend of presence of swordfish

329 larvae in the fast-moving boundary currents and larger larvae occurring in the eastern extent of

330 the Loop Current supports the assertion that these boundary currents provide a means to transport

331 larvae further along the western boundary current system of the Atlantic. Data from the NOAA

332 Pelagic Observer Program indicate that the northern Gulf of Mexico and coastal Atlantic waters

333 of the southeastern United States are predominately occupied by juvenile swordfish (80-130 cm;

334 Muhling et al., 2015). Multiple studies have also indicated that the northern Gulf of Mexico and

335 the waters off the southeastern United States, particularly the Charleston Bump, represent

336 juvenile habitat (Cramer, 2001; Govoni et al., 2003). These boundary currents can thus serve a

337 dual purpose as habitat for swordfish larvae and a mechanism to transport larvae toward their

338 juvenile habitat.

339 Transport of swordfish larvae to juvenile habitat from spawning in or near fast-moving

340 boundary currents well fits the member vagrant hypothesis as larvae spawned in varying

341 locations throughout the Caribbean, Gulf of Mexico, and Straits of Florida will likely be

342 transported to similar locations to begin the later stages of development (Sinclair, 1988).

343 However, swordfish in the North Atlantic are still genetically identified as one population, thus

344 the boundary currents alone do not represent a complete closure of this population because North 
345 Atlantic swordfish also spawn south of the Sargasso Sea which likely transports larvae to 346 additional juvenile habitat in the southeastern Caribbean (Arocha, 1997; Bremer et al., 2005;

347 Arocha, 2007). Swordfish which spawn near these boundary currents and those that spawn in the 348 Sargasso Sea are considered different spawning groups and mixing among the two spawning 349 groups may not occur until the fish move farther north to adult foraging grounds (Arocha, 2007). 350 Furthermore, adult swordfish need to be able to detect these boundary currents while they 351 are at their day-time depths (up to $900 \mathrm{~m}$ ) to ensure they remain in proximity to preferred 352 spawning locations. These fish may be able to remain near the western boundary current system 353 through sensing temperature gradients both near the surface and at depth (Podesta et al., 1993; 354 Sheinbaum et al., 2002; Carrillo et al., 2016). Therefore, large current regimes, such as the 355 Yucatan Current, may represent as spatially stable and easily identifiable region for swordfish to 356 spawn. Fecund swordfish and swordfish eggs are often caught near these boundary currents, 357 particularly those of the Yucatan Current, furthering evidence that these boundaries represent 358 spawning habitat (Arocha, 1997; 2007; Leyva-Cruz et al., 2016). Small swordfish larvae were 359 caught within the boundary currents in multiple regions and the size of swordfish larvae also 360 tends to increase as they are further downstream in the boundary current systems, supporting the 361 assertion that these boundary currents are important oceanographic features for swordfish 362 spawning. While presence of larvae in these boundaries does not directly translate to adult 363 swordfish presence, the presence of swordfish eggs and catches of fecund adult swordfish 364 suggest these current boundaries are important for both swordfish spawning and larval habitat. 365 The relationship between catchability of swordfish larvae and fraction of lunar 366 illumination suggest a connection between the lunar phase and time of spawning of swordfish. 367 Highest catchability of small (65\% of larvae $<6 \mathrm{~mm} \mathrm{SL})$ swordfish larvae occurred during 
368 crescent and gibbous moon phases. The high catches of larvae during crescent and gibbous

369 moons could be a result of spawning during the quarter moon phases given an estimate of three

370 days prior to hatching and the subsequent growth rate of swordfish larvae (Yasuda et al., 1978;

371 Enfield and Mayer, 1997; Govoni et al., 2003). Multiple reports show catch per unit effort

372 (CPUE) increases for the swordfish fishery around first and third quarter moon phases, possibly

373 indicative of spawning as CPUE is often highest for fisheries during spawning (dos Santos and

374 Garcia, 2005; Yukami et al., 2009; Poisson et al., 2010; Erisman et al., 2011). The strong

375 correlation of night time depth of adult swordfish with lunar illumination supports the hypothesis

376 that the lunar cycle influences the behavior of swordfish (Dewar et al., 2011; Lerner et al.,

377 2013). While the exact spawning time of swordfish is uncertain, our data reveal the importance

378 of lunar illumination for the spawning of swordfish for the first time.

379 The peak in larval swordfish catch at noon was consistent with observations from Habtes

380 et al. (2014; Fig. 5e). Diel variability in catch of ichthyoplankton in surface water is often due to

381 diel vertical migration of ichthyoplankton. However, the diet of swordfish larvae suggests a

382 shallow water existence as young larvae consume neritic copepods and larger larvae are

383 piscivorous, suggesting a neustonic lifestyle (Arata, 1954; Gorbunova, 1969; Govoni et al.,

384 2003). Thus, while it is difficult to elucidate a reason for the diel trend in larval swordfish catch,

385 the literature suggests that large scale vertical migrations are unlikely and our results may be an

386 artifact of sampling otherwise favorable habitat at these hours.

387 Mapping and habitat models from this study corroborate previous work indicating that

388 there are oceanographic features throughout the Gulf of Mexico and western Caribbean Sea that

389 serve as favorable habitat for swordfish larvae. Future work to better understand the habitat

390 associations of swordfish larvae should focus on sampling multiple oceanographic features to 
391 attain better knowledge of their larval distribution throughout the Caribbean Current, Yucatan 392 Current, and Loop Current. Obtaining finer resolution data on the exact water masses and fronts 393 utilized by these fish for spawning and larval habitat can be used to protect regions from fishing 394 pressure and shipping disturbance to assist the reproductive success of these fish. However, 395 intra-annual variability of swordfish spawning needs to be assessed, thus sampling should occur 396 January through July with a focus on both eggs and larvae in order to elucidate this variation 397 (Govoni et al., 2003; Rooker et al., 2012; Neilson et al., 2014). Habitat models may also be 398 constructed through different methodologies to incorporate historical data from SEAMAP and 399 Marine Resources Monitoring, Assessment, and Prediction program (MARMAP) data sets but 400 these must be done carefully to ensure the physical parameters are accurate and precise. The 401 years of sampling in this study (2010-2012) also occurred at a time of low abundance in the 402 North Atlantic swordfish stock, though recovery of the stock was likely occurring (ICCAT, 403 2014). Future studies should assess how and if habitat models of larvae may change as the stock 404 size fluctuates and if the quantity of favorable habitat as predicted by these models relates to 405 recruitment of this stock.

406 We present new developments in the understanding of the early life history of swordfish.

407 This study supports and expands the spatial extent of the existing hypothesis that larval 408 swordfish habitat is associated with boundary currents in the western Caribbean Sea and Gulf of 409 Mexico, primarily the Caribbean, Yucatan, and Loop Currents and that these currents may 410 provide a means to transport swordfish larvae toward larval and juvenile habitats. Assessment of 411 the standard length of larvae caught throughout the sampling region indicated that multiple 412 spawning locations likely occur, with small larvae caught north of Honduras, the Yucatan 413 Channel, and in the north central Gulf of Mexico in northern and western extents of the Loop 
414 current. We also indicate a connection between lunar illumination and swordfish spawning, the

415 first assertion of such a connection to our knowledge. While higher resolution data should be

416 used to further identify smaller scale associations of swordfish larvae with oceanographic

417 features, the identification of larval habitat from this study is a step toward an improved

418 understanding of this commercially and ecologically important species. This study provides

419 valuable information about the larval habitat of a commercially important species so that

420 estimations of anthropogenic influences on larval habitat can be made, including severely

421 deleterious events such as oil spills.

422

423 ACKNOWLEDGMENTS:

424 The authors would like to thank the lab at the NOAA Fisheries Oceanography for

425 Recruitment, Climate and Ecosystem Studies (FORCES), the taxonomists at the Departamento

426 de Sistemática y Ecología Acuática at El Colegio de la Frontera Sur (ECOSUR), the staff at the

427 Polish Plankton Sorting and Identification Center in Szczecin, Poland, and the officers and crew

428 of the NOAA ship Gordon Gunter that facilitated data collection on the SEAMAP cruises. The

429 authors would also like to thank J Serafy for useful comments to improve this manuscript. This

430 research was carried out under the auspices of the Cooperative Institute for Marine and

431 Atmospheric Studies, University of Miami and partially funded by NASA (NNX11AP76G,

432 NNX08AL06G), and the NOAA Southeast Fisheries Science Center. No authors have any

433 conflicts of interest to declare. 


\section{REFERENCES:}

Arata Jr, G. F. (1954). A contribution to the life history of the swordfish, Xiphias gladius Linnaeus, from the South Atlantic coast of the United States and the Gulf of Mexico. Bulletin of Maine Science 4, 183-243.

Arocha, F. (1997). The reproductive dynamics of swordfish Xiphias gladius L and management implications in the northwestern Atlantic. $\mathrm{PhD}$ thesis, University of Miami

Arocha, F. (2007). Swordfish reproduction in the Atlantic Ocean: an overview. Gulf and Caribbean Research, 19, 21-36.

Bakun, A. (1996). Patterns in the ocean. La Paz, Mexico: California Sea Grant, in cooperation with Centro de Investigaciones Biologicas del Noroeste

Bakun, A. (2006). Fronts and eddies as key structures in the habitat of marine fish larvae: opportunity, adaptive response and competitive advantage. Scientia Marina, 70, 105-122.

Bailey, K. M., \& Houde, E. D. (1989). Predation on eggs and larvae of marine fishes and the recruitment problem. Advances in Marine Biology, 25, 1-83.

Barry, S. C., \& Welsh, A. H. (2002). Generalized additive modelling and zero inflated count data. Ecological Modelling 157, 179-188.

Berger, T. J., P. Hamilton, J. J. Singer, R. R. Leben, G. H. Born \& C. A. Fox (1996), Louisiana/Texas Shelf Physical Oceanography Program Eddy Circulation Study: Final Synthesis Report. Volume I: Technical Report, OCS Study MMS 96-0051, U.S. Dept. of the Interior, Minerals Management Service, Gulf of Mexico OCS Region, New Orleans, LA. 324 pp.

Bremer, J. A., Mejuto, J., Gómez-Márquez, J., Boán, F., Carpintero, P., Rodríguez, J. M., Viñas, J., Greig, T.W., \& Ely, B. (2005). Hierarchical analyses of genetic variation of samples from breeding and feeding grounds confirm the genetic partitioning of northwest Atlantic and South Atlantic populations of swordfish (Xiphias gladius L.). Journal of Experimental Marine Biology and Ecology, 327, 167-182.

Burnham, K. P., \& Anderson, D. R. (2002). Akaike Weights. In Model Selection and Multimodel Inference: A Practical Information-Theoretic Approach Second Edition (pp. 60-65). Springer:

New York.

Candela, J., Sheinbaum, J., Ochoa, J., Badan, A., \& Leben, R. (2002). The potential vorticity flux through the Yucatan Channel and the Loop Current in the Gulf of Mexico. Geophysical Research Letters, 29(22).

Carrillo, L., Johns, E. M., Smith, R. H., Lamkin, J. T., \& Largier, J. L. (2016). Pathways and hydrography in the Mesoamerican Barrier Reef System Part 2: Water masses and thermohaline structure. Continental Shelf Research, 120, 41-58.

Carton, J. A., \& Chao, Y. (1999). Caribbean Sea eddies inferred from TOPEX/Poseidon altimetry and a 1/6 Atlantic Ocean model simulation. Journal of Geophysical Research, 104(C4), 7743-7752. 
Chancollon, O., Pusineri, C., \& Ridoux, V. (2006). Food and feeding ecology of Northeast Atlantic swordfish (Xiphias gladius) off the Bay of Biscay. ICES Journal of Marine Science: Journal du Conseil. 63, 1075-1085.

Chassignet, E. P., Hurlburt, H. E., Smedstad, O. M., Halliwell, G. R., Hogan, P. J., Wallcraft, A. J., Baraille, R., \& Bleck, R. (2007). The HYCOM (hybrid coordinate ocean model) data assimilative system. Journal of Marine Systems, 65, 60-83.

Cramer, J. (2001). Geographic distribution of longline effort and swordfish discard rates in the straits of Florida and oceanic waters of the continental shelf, slope, and Blake Plateau off Georgia and the Carolinas from 1991 to 1995. In American Fisheries Society Symposium, 97-104 Cushing, D. H. (1969). The regularity of the spawning season of some fishes. ICES Journal of Marine Science: Journal du Conseil, 33, 81-92.

Cushing, D. H. (1990). Plankton production and year-class strength in fish populations: an update of the match/mismatch hypothesis. Advances in Marine Biology, 26, 249-293.

Dewar, H., Prince, E. D., Musyl, M. K., Brill, R. W., Sepulveda, C., Luo, J., Foley,D., Orbesen, E.S., Dromeier, M.L.,Nasby-Lucas, N., Snodgrass, D., Luars, R.M., Hoolihan, J.P. Block, B.A., \& McNaughton, L.M. (2011). Movements and behaviors of swordfish in the Atlantic and Pacific Oceans examined using pop up satellite archival tags. Fisheries Oceanography 20, 219-241.

Domingues, R., Goni, G., Bringas, F., Muhling, B., Lindo Atichati, D., \& Walter, J. (2016). Variability of preferred environmental conditions for Atlantic bluefin tuna (Thunnus thynnus) larvae in the Gulf of Mexico during 1993-2011. Fisheries Oceanography, 25, 320-336.

Ducet, N., \& Le Traon, P. Y. (2001). A comparison of surface eddy kinetic energy and Reynolds stresses in the Gulf Stream and the Kuroshio Current systems from merged TOPEX/Poseidon and ERS-1/2 altimetric data. Journal of Geophysical Research-Oceans, 106, 16603-16622.

Enfield, D. B., \& Mayer, D. A. (1997). Tropical Atlantic sea surface temperature variability and its relation to El Niño Southern Oscillation. Journal of Geophysical Research-Oceans 102, 929945.

Erisman, B. E., Allen, L. G., Claisse, J. T., Pondella, D. J., Miller, E. F., \& Murray, J. H. (2011). The illusion of plenty: hyperstability masks collapses in two recreational fisheries that target fish spawning aggregations. Canadian Journal of Fisheries and Aquatic Sciences, 68, 1705-1716.

Feng, J., Durant, J. M., Stige, L. C., Hessen, D. O., Hjermann, D. Ø., Zhu, L., Llope, M., \& Stenseth, N.C. (2015). Contrasting correlation patterns between environmental factors and chlorophyll levels in the global ocean. Global Biogeochemical Cycles 29, 2095-2107

Garcia, H. E., \& Gordon, L. I. (1992). Oxygen solubility in seawater: Better fitting equations. Limnology and Oceanography, 37, 1307-1312.

Gorbunova, N. N. (1969). Breeding grounds and food of the larvae of the swordfish [Xiphias gladius Linné (Pisces, Xiphilidae)]. Problems in Ichthyology, 9, 375-387.

Govoni, J. J., Stender, B. W., \& Pashuk, O. (2000). Distribution of larval swordfish, Xiphias gladius, and probable spawning off the southeastern United States. Fishery Bulletin, 98, 64-74 
Govoni, J. J., Laban, E. H., \& Hare, J. A. (2003). The early life history of swordfish (Xiphias gladius) in the western North Atlantic. Fishery Bulletin, 101, 778-789.

Govoni, J. J., Hare, J. A., Davenport, E. D., Chen, M. H., \& Marancik, K. E. (2010). Mesoscale, cyclonic eddies as larval fish habitat along the southeast United States shelf: a Lagrangian description of the zooplankton community. ICES Journal of Marine Science: Journal du Conseil. $67,403-411$.

Grall, C., De Sylva, D. P., \& Houde, E. D. (1983). Distribution, relative abundance, and seasonality of swordfish larvae. Transactions of American Fisheries Society, 112, 235-246.

Habtes, S., Muller Karger, F. E., Roffer, M. A., Lamkin, J. T., \& Muhling, B. A. (2014). A comparison of sampling methods for larvae of medium and large epipelagic fish species during spring SEAMAP ichthyoplankton surveys in the Gulf of Mexico. Limnology and Oceanography: Methods, 12, 86-101.

Hamilton, P., Berger, T.J., Singer, J.J., Waddell, E., Churchill, J.H., Leben, R.R., Lee, T.N., \& Sturges, W., (2000). DeSoto Canyon Eddy Intrusion Study, Final Report, Volume II: Technical Report, OSC Study MMS 2000-080. US Department of the Interior, Minerals Management Service, Gulf of Mexico OCS Region, New Orleans, LA, 275pp.

Hernandez Jr, F. J., Powers, S. P., \& Graham, W. M. (2010). Seasonal variability in ichthyoplankton abundance and assemblage composition in the northern Gulf of Mexico off Alabama. Fishery Bulletin, 108(2), 193-207.

Houde, E. D., Dowd, J. C., Berkeley, C. E., Houde, S. A. E. D., \& James, C.(1979). Ichthyoplankton abundance and diversity in the eastern Gulf of Mexico (No. 574.92 I2).

Houde, E. D. (1989). Comparative growth, mortality, and energetics of marine fish larvae: temperature and implied latitudinal effects. Fishery Bulletin, 87, 471-495.

Huberty, C. J. (1994). Applied discriminant analysis (Vol. 297). Wiley-Interscience.

Hurlburt, H. E., \& Thompson, J.D. (1982). The dynamics of the loop current and shed eddies in a numerical model of the Gulf of Mexico. In: Hydrodynamics of Semi-enclosed Seas, ed. J. C. J. Nihoul, Elsevier Science, New York, NY., 243-297

International Commission for the Conservation of Atlantic Tunas (2014). Report of the ICCAT swordfish stock assessment session.

Ito, R. Y., Dollar, R. A., \& Kawamoto, K. E. (1998). The Hawaii-based longline fishery for swordfish, Xiphias gladius. Biology and fisheries of swordfish, Xiphias gladius. NOAA Tech Rep NMFS, 142, 77-88.

Leben, R. R., \& Born, G. H. (1993). Tracking Loop Current eddies with satellite altimetry. Advances in Space Research, 13, 325-333.

Leben, R. R., Born, G. H., \& Engebreth, B. R. (2002). Operational altimeter data processing for mesoscale monitoring. Marine Geodesy, 25, 3-18. 
Lerner, J. D., Kerstetter, D. W., Prince, E. D., Talaue-McManus, L., Orbesen, E. S., Mariano, A., Snodgrass, D., \& Thomas, G. L. (2013). Swordfish vertical distribution and habitat use in relation to diel and lunar cycles in the western North Atlantic. Transactions of the American Fisheries Society, 142, 95-104.

Leyva-Cruz, E., Vásquez-Yeomans, L., Carrillo, L., \& Valdez-Moreno, M. (2016). Identifying pelagic fish eggs in the southeast Yucatan Peninsula using DNA barcodes. Genome, 59, $1117-$ 1129.

Megalofonou, P., Dean, J. M., De Metrio, G., Wilson, C., \& Berkeley, S. (1995). Age and growth of juvenile swordfish, Xiphias gladius Linnaeus, from the Mediterranean Sea. Journal of Experimental Marine Biology and Ecology, 188(1), 79-88.

Muhling, B. A., Lamkin, J. T., \& Roffer, M. A. (2010). Predicting the occurrence of Atlantic bluefin tuna (Thunnus thynnus) larvae in the northern Gulf of Mexico: building a classification model from archival data. Fisheries Oceanography, 19, 526-539.

Muhling, B. A., Lamkin, J. T., \& Richards, W. J. (2012). Decadal-scale responses of larval fish assemblages to multiple ecosystem processes in the northern Gulf of Mexico. Marine Ecology Progress Series, 450, 37-53.

Muhling, B. A., Liu, Y., Lee, S. K., Lamkin, J. T., Malca, E., Llopiz, J.K., Ingram G. W., Quattro J. M., Walter, J. F., Doering, K., Roffer, M. A., \& Muller-Karger, F. (2015). Past, Ongoing and Future Research on Climate Change Impacts on Tuna and Billfishes in the Western Atlantic. Collect. Vol. Sci. Pap. ICCAT, 71, 147-174.

Nakamura, I. (1985) Billfishes of the world. FAO Fish. Synop. 125, 58 p

NASA Goddard Space Flight Center, Ocean Ecology Laboratory, Ocean Biology Processing

Group. Moderate-resolution Imaging Spectroradiometer (MODIS) Aqua Chlorophyll Data; 2014 Reprocessing. NASA OB.DAAC, Greenbelt, MD, USA. doi: 10.5067/AQUA/MODIS/L3M/CHL/2014. Accessed on 03/2016

Neilson, J. D., Loefer, J., Prince, E. D., Royer, F., Calmettes, B., Gaspar, P., Lopez, R., \& Andrushchenko, I. (2014). Seasonal Distributions and Migrations of Northwest Atlantic Swordfish: Inferences from Integration of Pop-Up Satellite Archival Tagging Studies. PloS one, 9, e112736.

Oey, L. Y., Ezer, T., \& Lee, H. C. (2005). Loop Current, rings and related circulation in the Gulf of Mexico: A review of numerical models and future challenges. Circulation in the Gulf of Mexico: Observations and models, Washington D.C: AGU

Palko, R. J., G. L. Beardsley, \& W. J. Richards. (1981) Synopsis of the biology of the swordfish Xiphias gladius Linnaeus. U.S. Dep. Commer. NOAATech. Rep. NMFS Circ. 441.

Podestá, G. P., Browder, J. A., \& Hoey, J. J. (1993). Exploring the association between swordfish catch rates and thermal fronts on US longline grounds in the western North Atlantic. Continental Shelf Research 13, 253-277. 
Poisson, F., Gaertner, J. C., Taquet, M., Durbec, J. P., and Bigelow, K. (2010). Effects of lunar cycle and fishing operations on longline-caught pelagic fish: fishing performance, capture time, and survival of fish. Fishery Bulletin 108, 268-281.

Rathmell, K. (2007). The influence of the Loop Current on the diversity, abundance, and distribution of zooplankton in the Gulf of Mexico. Master's thesis, University of South Florida.

Relini, L. O., Palandri, G., \& Garibaldi, F. (2003). Reproductive parameters of the Mediterranean swordfish. Bioiogia . Marina Mediterranea, 10(2), 210-222.

Richards, W. J., McGowan, M. F., Leming, T., Lamkin, J. T., \& Kelley, S. (1993). Larval fish assemblages at the Loop Current boundary in the Gulf of Mexico. Bulletin of Marine Science, 53, 475-537.

Richardson, P. L. (2005). Caribbean Current and eddies as observed by surface drifters. DeepSea Research Pt. II, 52, 429-463.

Richardson, D. E., Llopiz, J. K., Leaman, K. D., Vertes, P. S., Muller-Karger, F. E., \& Cowen, R. K. (2009). Sailfish (Istiophorus platypterus) spawning and larval environment in a Florida Current frontal eddy. Progress in Oceanography, 82, 252-264.

Richardson, D. E., Llopiz, J. K., Guigand, C. M., \& Cowen, R. K. (2010). Larval assemblages of large and medium-sized pelagic species in the Straits of Florida. Progress in Oceanography, 86, 8-20.

Roberts, J. J., Best, B. D., Dunn, D. C., Treml, E. A., \& Halpin, P. N. (2010). Marine Geospatial Ecology Tools: An integrated framework for ecological geoprocessing with ArcGIS, Python, R, MATLAB, and C++. Environmental Modelling \& Software, 25, 1197-1207.

Rooker, J. R., Simms, J. R., Wells, R. D., Holt, S. A., Holt, G. J., Graves, J. E., \& Furey, N. B. (2012). Distribution and habitat associations of billfish and swordfish larvae across mesoscale features in the Gulf of Mexico. PloS one, 7, e34180.

dos Santos, M. N., \& Garcia, A. (2005). The influence of the moon phase on the CPUEs for the Portuguese swordfish (Xiphias gladius L., 1758) fishery. Col. Vol. Sci. Pap. ICCAT, 58, 14661469.

Scott, W. B., \& Tibbo, S. N. (1968). Food and feeding habits of swordfish, Xiphias gladius, in the western North Atlantic. Journal of the Fisheries Board of Canada, 25, 903-919.

Sheinbaum, J., Candela, J., Badan, A., \& Ochoa, J. (2002). Flow structure and transport in the Yucatan Channel. Geophysical Research Letters 29, 101-104

Simms, J. R., Rooker, J. R., Holt, S. A., Holt, G. J., \& Bangma, J. (2010). Distribution, growth, and mortality of sailfish (Istiophorus platypterus) larvae in the northern Gulf of Mexico. Fishery Bulletin, 108, 478-490.

Sinclair, M. (1988). Marine populations: an essay on population regulation and speciation. Washington Press. 
Solanki, H. U., Bhatpuria, D., \& Chauhan, P. (2015). Integrative Analysis of AltiKa-SSHa, MODIS-SST, and OCM-Chlorophyll Signatures for Fisheries Applications. Marine Geodesy, $38,672-683$.

Sundblad, G., Härmä, M., Lappalainen, A., Urho, L., \& Bergström, U. (2009). Transferability of predictive fish distribution models in two coastal systems. Estuarine, Coastal and Shelf Science, 83, 90-96.

Taylor, R. G., \& Murphy, M. D. (1992). Reproductive biology of the swordfish Xiphias gladius in the Straits of Florida and adjacent waters. Fishery Bulletin, 90, 809-816.

Teo, S. L., Boustany, A. M., \& Block, B. A. (2007). Oceanographic preferences of Atlantic bluefin tuna, Thunnus thynnus, on their Gulf of Mexico breeding grounds. Marine Geodesy, 152, 1105-1119.

Vukovich, F. M., \& Maul, G. A. (1985). Cyclonic eddies in the eastern Gulf of Mexico. Journal of Physical Oceanography, 15, 105-117.

Ward, P., Porter, J. M., \& Elscot, S. (2000). Broadbill swordfish: status of established fisheries and lessons for developing fisheries. Fish and Fisheries, 1, 317-336.

Wood, S. N. (2008). Fast stable direct fitting and smoothness selection for generalized additive models. Journal of the Royal Statistical Society Series B Statistical Methodology 70, 495-518.

Wood, S.N. (2017). Generalized additive models: an introduction with R. CRC press.

Yasuda F, Kohno H, Yatsu A, Ida H, Arena P, Li Greci F, Taki Y (1978) Embryonic and early larval stages of the swordfish, Xiphias gladius, from the Mediterranean. Journal of the Tokyo University of Fisheries, 65, 91-97

Yukami, R., Ohshimo, S., Yoda, M., \& Hiyama, Y. (2009). Estimation of the spawning grounds of chub mackerel Scomber japonicus and spotted mackerel Scomber australasicus in the East China Sea based on catch statistics and biometric data. Fisheries Science, 75, 167-174.

Zuur, A. F., Ieno, E. N., Walker, N. J., Saveliev, A. A., \& Smith, G. M. (2009). Zero-truncated and zero-inflated models for count data. In Mixed effects models and extensions in ecology with $R$ (pp. 261-293). New York: Springer

Zuur, A.F. (2012) A beginner's guide to generalized additive models with R. Newburgh: Highland Statistics Limited. 


\section{TABLES:}

Table 1: Environmental parameters used in model formation with sources and metrics listed. All in-situ data were collected using a Seabird SBE 9/11 Plus CTD (conductivity, temperature, and depth) equipped with a dissolved oxygen sensor (SBE 43).

\begin{tabular}{|llllll|}
\hline Parameter & Source & Minimum & Maximum & Mean & Median \\
\hline Eddy Kinetic Energy $\left(\mathrm{m}^{2} \mathrm{~s}^{-2}\right)$ & HYCOM & 0.00 & 1.54 & 0.14 & 0.06 \\
Sea Surface Height Anomaly $(\mathrm{m})$ & HYCOM & -0.45 & 0.64 & -0.09 & -0.19 \\
Temperature at $5 \mathrm{~m}\left({ }^{\circ} \mathrm{C}\right)$ & In-situ & 21.45 & 28.35 & 26.39 & 26.66 \\
Salinity at $5 \mathrm{~m}$ & In-situ & 33.04 & 36.70 & 36.04 & 36.02 \\
Oxygen at $5 \mathrm{~m}\left(\mathrm{mg} \mathrm{L}^{-1}\right)$ & In-situ & 6.13 & 7.46 & 6.60 & 6.61 \\
Chlorophyll $a\left(\mathrm{mg} \mathrm{m}^{-3}\right)$ & MODIS & 0.04 & 0.57 & 0.11 & 0.10 \\
Depth $(\mathrm{m})$ & NCEI & 204.00 & 7124.00 & 2177.24 & 2140.50 \\
\hline
\end{tabular}


Table 2: Details of the backward stepwise Akaike Information Criterion ( $\triangle \mathrm{AIC}$ ) model selection process including the original model and the subsequent top three models for each iteration as determined by greatest change in AIC and deviance explained. The overall best fit model for the final iteration is in bold. ORT represents oxygen residuals from temperature. CRT (RE) represents chlorophyll $a$ residuals from temperature as a random effect. 


\begin{tabular}{|c|c|c|c|c|}
\hline Iteration & Variables Included & $\operatorname{AIC}(\Delta)$ & $\mathrm{DE}(\Delta)$ & Akaike Weight $\left(w_{i}\right)$ \\
\hline 1 & Temperature, ORT, CRT (RE), SSHA, EKE, Lun Illum, Salinity, Hour, Depth, Year, Long/Lat(TE) & $296.33(0)$ & $33.6(0)$ & 0.126 \\
\hline 1 & Temperature, ORT, CRT (RE), SSHA, EKE, Lun Illum, Salinity, Hour, Depth, Long/Lat(TE) & $295.04(-1.29)$ & $33.1(-0.5)$ & 0.228 \\
\hline 1 & Temperature, CRT (RE), SSHA, EKE, Lun Illum, Salinity, Hour, Depth, Year, Long/Lat(TE) & 294.61(-1.72) & $33.2(-0.3)$ & 0.282 \\
\hline 1 & Temperature, ORT, CRT (RE), SSHA, EKE, Lun Illum, Hour, Depth, Year, Long/Lat(TE) & $294.53(-1.80)$ & $33.5(-0.1)$ & 0.294 \\
\hline 2 & Temperature, ORT, CRT (RE), SSHA, EKE, Lun Illum, Hour, Depth Year, Long/Lat(TE) & 294.53(-1.80) & $33.5(-0.1)$ & 0.173 \\
\hline 2 & Temperature, ORT, CRT (RE), SSHA, EKE, Lun Illum, Salinity, Hour, Year, Long/Lat(TE) & $296.54(0.210)$ & $30.5(-3.1)$ & 0.063 \\
\hline 2 & Temperature, ORT, CRT (RE), SSHA, EKE, Lun Illum, Hour, Depth, Long/Lat(TE) & $293.43(-2.89)$ & $33(-0.6)$ & 0.299 \\
\hline 2 & Temperature, CRT (RE), SSHA, EKE, Lun Illum, Hour, Depth, Year, Long/Lat(TE) & $292.74(-3.58)$ & $33.2(-0.3)$ & 0.423 \\
\hline 3 & Temperature, CRT (RE), SSHA, EKE, Lun Illum, Hour, Depth, Year, Long/Lat(TE) & 292.74(-3.58) & $33.2(-0.3)$ & 0.217 \\
\hline 3 & Temperature, CRT (RE), SSHA, Lun Illum, Hour, Depth, Year, Long/Lat(TE) & $296.66(0.330)$ & $29.4(-4.2)$ & 0.008 \\
\hline 3 & Temperature, CRT (RE) SSHA, EKE, Lun Illum, Salinity, Hour, Depth, Long/Lat(TE) & $292.1(-4.22)$ & $33.1(-0.5)$ & 0.298 \\
\hline 3 & Temperature, CRT (RE), SSHA, EKE, Lun Illum, Hour, Year, Long/Lat(TE) & $291.31(-5.01)$ & $33.1(-0.5)$ & 0.443 \\
\hline 4 & Temperature, CRT (RE), SSHA, EKE, Lun Illum,, Hour, Year, Long/Lat(TE) & $291.31(-5.01)$ & $33.1(-0.5)$ & 0.380 \\
\hline 4 & Temperature, CRT (RE), EKE, Lun Illum, Hour, Year, Long/Lat(TE) & 298(1.670) & $30(-3.6)$ & 0.013 \\
\hline 4 & Temperature, CRT (RE), SSHA, Lun Illum, Hour, Year, Long/Lat(TE) & 295.93(-0.39) & $29.4(-4.2)$ & 0.038 \\
\hline 4 & Temperature, CRT (RE), SSHA, EKE, Lun Illum, Hour, Long/Lat(TE) & $290.54(-5.78)$ & $33.1(-0.5)$ & 0.558 \\
\hline 5 & Temperature, CRT (RE), SSHA, EKE, Lun Illum, Hour, Long/Lat(TE) & 290.54(-5.78) & 33.1(-0.5) & 0.780 \\
\hline 5 & Temperature, SSHA, EKE, Lun Illum, Hour, Long/Lat(TE) & $298.64(2.31)$ & $30.6(-3)$ & 0.010 \\
\hline 5 & Temperature, CRT (RE), EKE, Lun Illum, Hour, Long/Lat(TE) & $299.3(2.970)$ & $29.2(-4.4)$ & 0.014 \\
\hline 5 & Temperature, CRT (RE), SSHA, Lun Illum, Hour, Long/Lat(TE) & 293.52(-2.81) & $33.6(0)$ & 0.176 \\
\hline
\end{tabular}


Table 3: Change in Akaike Information Criterion $(\triangle \mathrm{AIC})$ and deviance explained $(\triangle \mathrm{DE})$ for environmental and spatial parameters in the final model.

\begin{tabular}{|clll|}
\hline Final Model & Variable & $\Delta$ AIC & $\Delta \mathrm{DE}$ \\
\hline AIC: 290.542 & Hour of Sampling & 19.02 & $6.3 \%$ \\
DE: 33.1\% & Fraction of Lunar Illumination & 17.91 & $7.7 \%$ \\
& Latitude, Longitude & 13.65 & $9.7 \%$ \\
& Temperature at 5 $\mathrm{m}\left({ }^{\circ} \mathrm{C}\right)$ & 9.58 & $2.0 \%$ \\
& Sea Surface Height Anomaly $(\mathrm{m})$ & 8.10 & $1.9 \%$ \\
& Eddy Kinetic Energy $\left(\mathrm{m}^{2} \mathrm{~s}^{-2}\right)$ & 2.98 & $0.1 \%$ \\
\hline
\end{tabular}




\section{FIGURE LEGENDS:}

Figure 1: Schematic map of the Gulf of Mexico and Caribbean Sea showing the major ocean currents. Colors depict mean sea surface temperature estimates from the Hybrid Ocean Coordinate Model (HYCOM) 1/12 ${ }^{\circ}$ Reanalysis from April and May of 2010.

Figure 2: Distribution of sampling locations in the Gulf of Mexico and Caribbean in April-May a)2010 b)2011 and c)2012. Red symbols (+) indicate stations sampled and were used as model input. Black symbols $(+)$ indicate stations sampled and were not used as model input due to sensor malfunctions and their shallow bathymetry $(<200 \mathrm{~m}$ depth). Red circles $\bullet$ indicate stations that showed presence of swordfish larvae and were used as model input. Black circles $\bullet$ indicate stations that showed presence of swordfish larvae and were not used as model input due to sensor malfunctions, lack of CTD casts, or their shallow bathymetry $(<200 \mathrm{~m}$ depth). Color scale indicative of sea surface temperature (SST).

Figure 3: Correlations between A) chlorophyll- $a$ and temperature at $5 \mathrm{~m}(\mathrm{r}=-0.49, \mathrm{p}<0.01$ and B) dissolved oxygen at $5 \mathrm{~m}$ and temperature at $5 \mathrm{~m}(\mathrm{r}=-0.74, \mathrm{p}<0.01)$.

Figure 4: Mean standard length of swordfish larvae by station caught in both neuston and S-10 nets from 2010-2012. Color scale indicative of sea surface temperature (SST).

Figure 5: The response curves for a) temperature at $\left.5 \mathrm{~m}\left({ }^{\circ} \mathrm{C}\right), \mathrm{b}\right)$ sea surface height anomaly $(\mathrm{m})$, c) eddy kinetic energy $\left.\left(\mathrm{m}^{2} \mathrm{~s}^{-2}\right), \mathrm{d}\right)$ fraction of lunar illumination with the dark circle indicating the new moon and the open circle representing the full moon, and e) hour of sampling, with the open circle indicating local noon.

Figure 6: Catch of swordfish larvae in the Loop Current in 2012 overlaid on sea surface height anomaly $(\mathrm{m})$. Red circles $(\bullet)$ indicate stations that showed presence of swordfish larvae. 


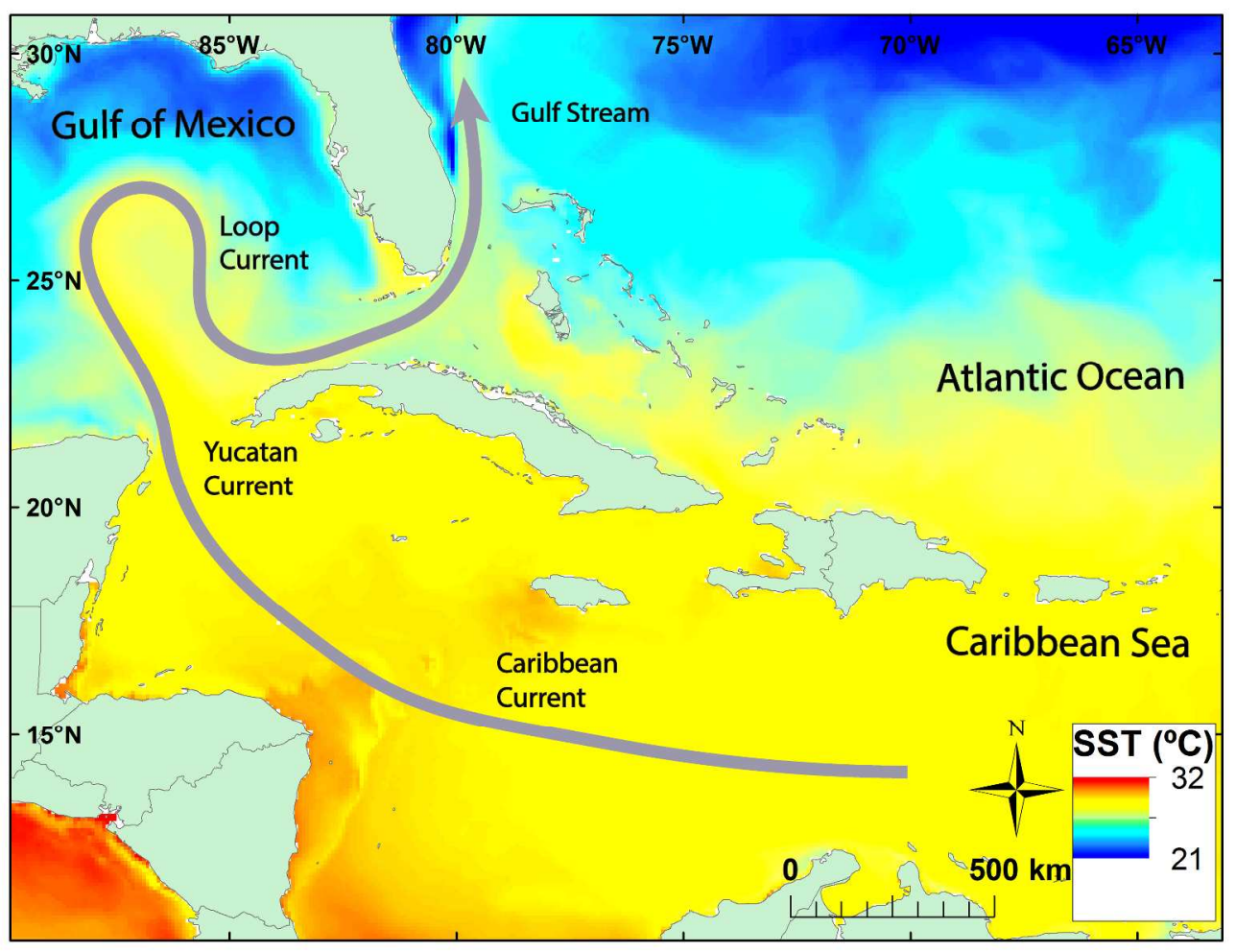

Figure 1: Schematic map of the Gulf of Mexico and Caribbean Sea showing the major ocean currents. Colors depict mean sea surface temperature estimates from the Hybrid Ocean Coordinate Model (HYCOM) 1/120 Reanalysis from April and May of 2010. 
Figure 2: Distribution of sampling locations in the Gulf of Mexico and Caribbean in April-May a)2010 b)2011 and c)2012. Red symbols (+) indicate stations sampled and were used as model input. Black symbols (+) indicate stations sampled and were not used as model input due to sensor malfunctions and their shallow bathymetry ( $<200 \mathrm{~m}$ depth). Red circles $\bullet$ indicate stations that showed presence of swordfish larvae and were used as model input. Black circles • indicate stations that showed presence of swordfish larvae and were not used as model input due to sensor malfunctions, lack of CTD casts, or their shallow bathymetry (< $200 \mathrm{~m}$ depth). Color scale indicative of sea surface temperature (SST). 


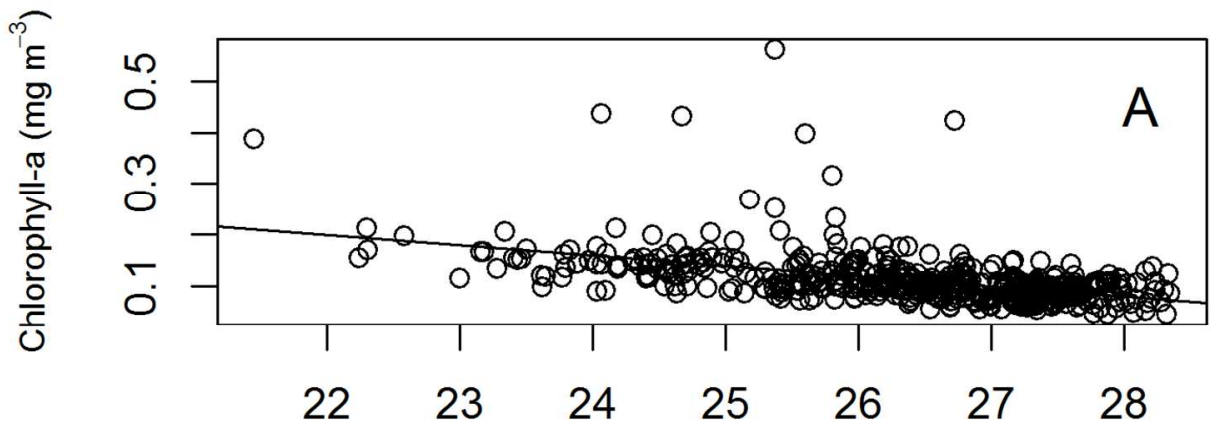

Temperature $\left({ }^{\circ} \mathrm{C}\right)$

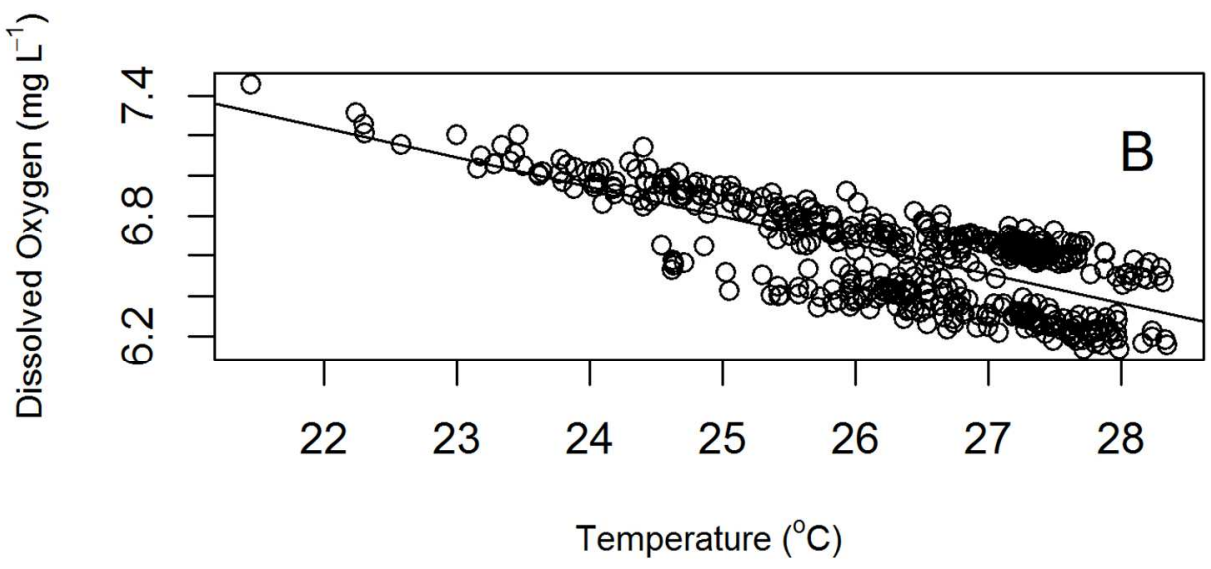

Figure 3: Correlations between A) chlorophyll- a and temperature at $5 \mathrm{~m}(r=-0.49, p<0.01$ and $B)$ dissolved oxygen at $5 \mathrm{~m}$ and temperature at $5 \mathrm{~m}(\mathrm{r}=-0.74, \mathrm{p}<0.01)$.

$127 \times 127 \mathrm{~mm}(300 \times 300$ DPI $)$ 


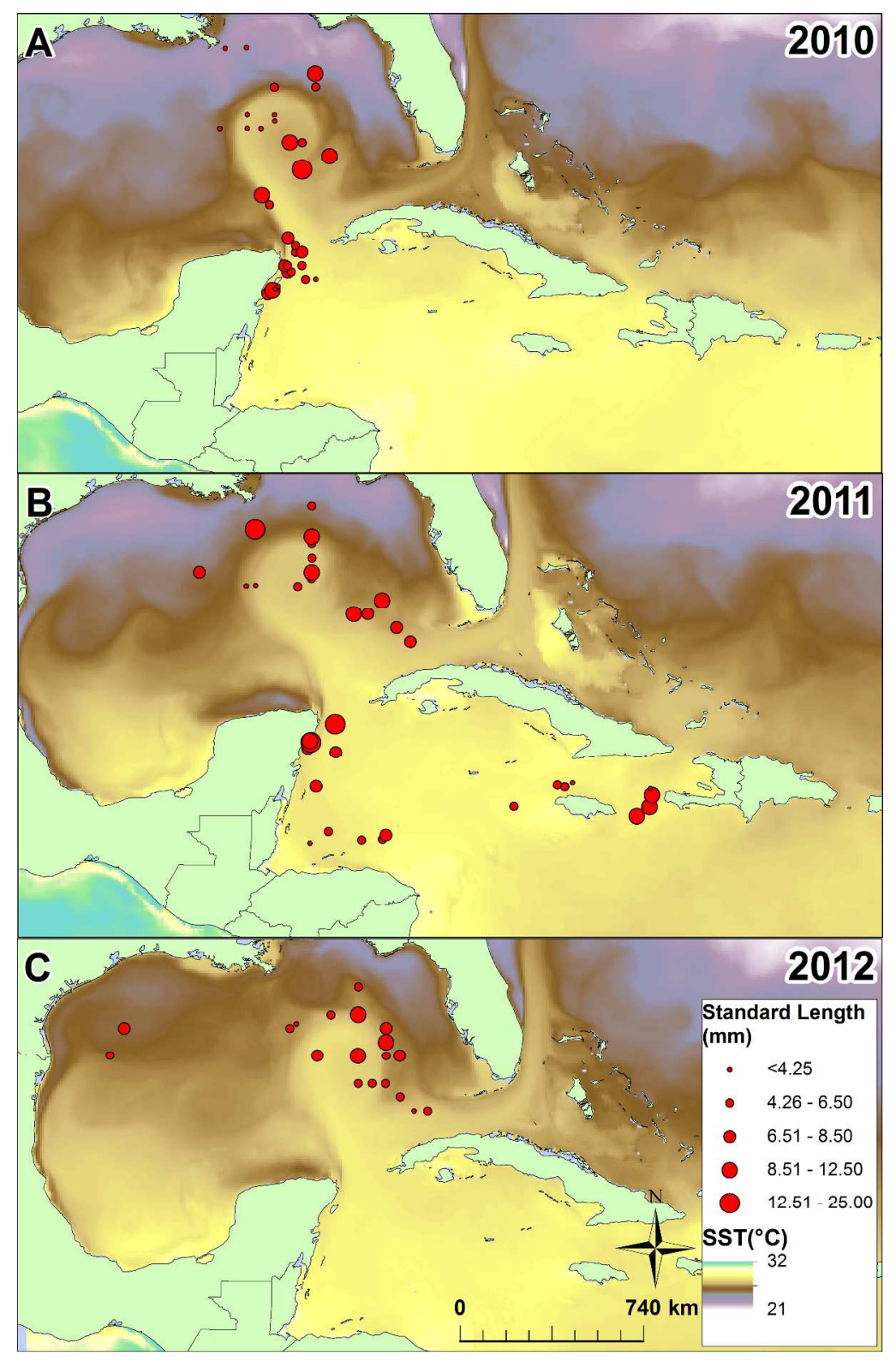

Figure 4: Mean standard length of swordfish larvae by station caught in both neuston and S-10 nets from 2010-2012. Color scale indicative of sea surface temperature (SST).

$279 \times 431 \mathrm{~mm}(300 \times 300 \mathrm{DPI})$ 

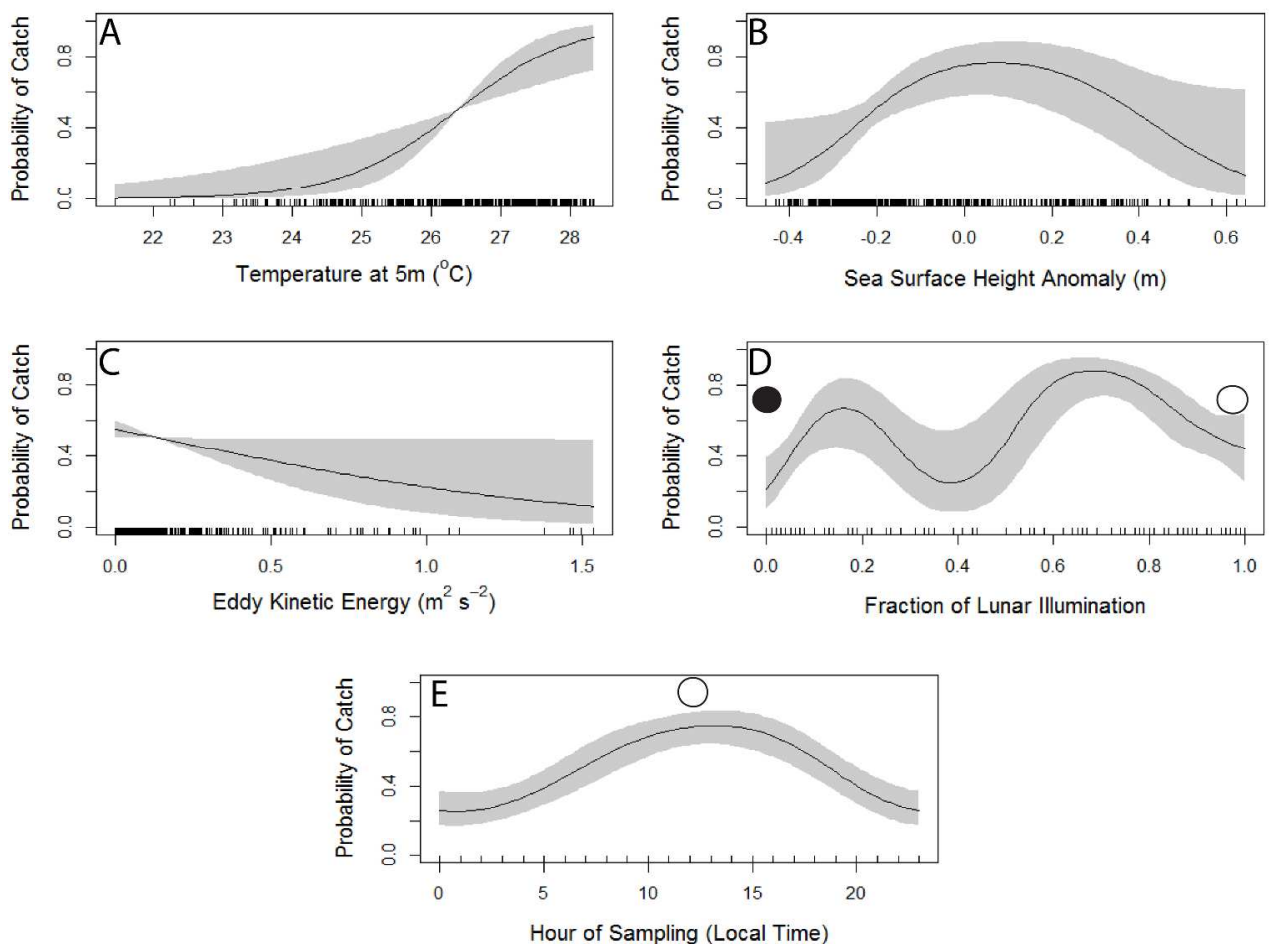

Figure 5: The response curves for a) temperature at $5 \mathrm{~m}(\mathrm{oC}), \mathrm{b})$ sea surface height anomaly $(\mathrm{m}), \mathrm{c})$ eddy kinetic energy ( $\mathrm{m} 2 \mathrm{~s}-2), \mathrm{d}$ ) fraction of lunar illumination with the dark circle indicating the new moon and the open circle representing the full moon, and e) hour of sampling, with the open circle indicating local noon. 


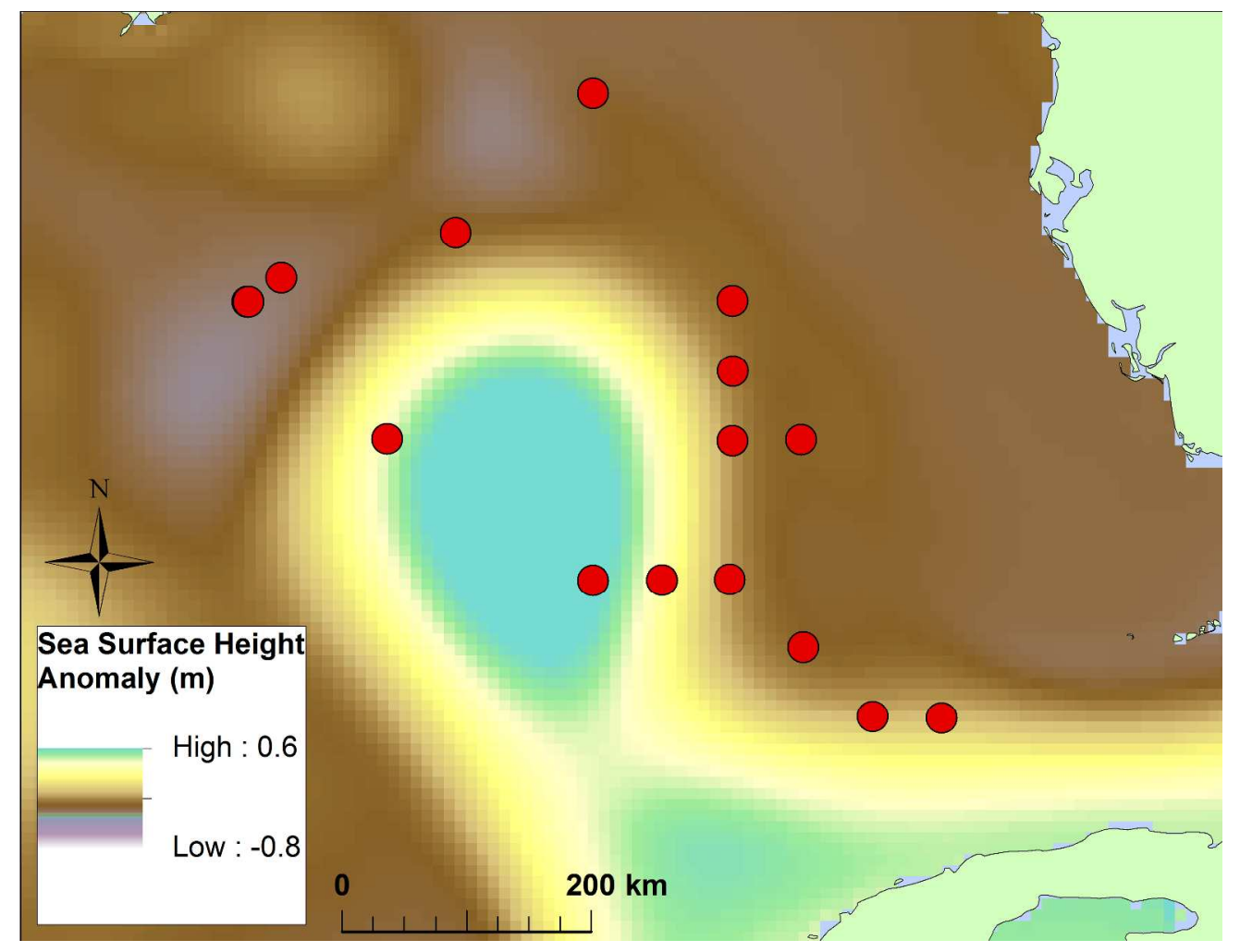

Figure 6: Catch of swordfish larvae in the Loop Current in 2012 overlaid on sea surface height anomaly $(\mathrm{m})$. Red circles $(\bullet)$ indicate stations that showed presence of swordfish larvae. 
Supp. Table 1: Standard length, time, and location of swordfish larvae used in this study. N represents number of swordfish larvae caught by the S-10 and neuston net at each station.

\begin{tabular}{|c|c|c|c|c|c|c|}
\hline Cruise & Date & Latitude & Longitude & Gear & $\mathbf{N}$ & Standard Length $(\mathrm{mm})$ \\
\hline GU1001 & $4 / 10 / 2010$ & 20.7711 & -86.5233 & S-10 & 5 & $7.32-10.56$ \\
\hline GU1001 & $4 / 10 / 2010$ & 20.7773 & -86.3936 & S-10 & 2 & $4.73-6.78$ \\
\hline GU1001 & $4 / 10 / 2010$ & 20.9998 & -86.6358 & Neuston & 1 & 6.66 \\
\hline GU1001 & $4 / 10 / 2010$ & 21.0061 & -86.004 & S-10 & 3 & $3.54-6.31$ \\
\hline GU1001 & $4 / 10 / 2010$ & 21.0061 & -86.004 & Neuston & 1 & 5.55 \\
\hline GU1001 & $4 / 10 / 2010$ & 21.0071 & -86.529 & S-10 & 3 & $4-6.1$ \\
\hline GU1001 & $4 / 11 / 2010$ & 21.4841 & -86.2376 & S-10 & 1 & 6.01 \\
\hline GU1001 & $4 / 11 / 2010$ & 21.4986 & -85.9988 & Neuston & 1 & 8.07 \\
\hline GU1001 & $4 / 11 / 2010$ & 21.7298 & -86.2341 & S-10 & 1 & 4.27 \\
\hline GU1001 & $4 / 11 / 2010$ & 21.9985 & -86.511 & S-10 & 2 & $4.57-11.51$ \\
\hline GU1001 & $4 / 12 / 2010$ & 23.2012 & -87.1788 & S-10 & 1 & 4.3 \\
\hline GU1001 & $4 / 13 / 2010$ & 23.4192 & -87.3669 & S-10 & 3 & $4.68-5.48$ \\
\hline GU1001 & $4 / 13 / 2010$ & 23.5531 & -87.458 & S-10 & 2 & $6.57-11.26$ \\
\hline GU1001 & $4 / 28 / 2010$ & 25.4893 & -85.998 & S-10 & 1 & 5.82 \\
\hline GU1001 & $4 / 28 / 2010$ & 25.4926 & -86.446 & S-10 & 1 & 10.95 \\
\hline GU1001 & $4 / 29 / 2010$ & 24.4922 & -85.9979 & S-10 & 2 & $3.72-25.68$ \\
\hline GU1001 & $4 / 29 / 2010$ & 24.9881 & -84.9955 & Neuston & 1 & 10.05 \\
\hline GU1001 & $4 / 8 / 2010$ & 19.994 & -87.2475 & S-10 & 3 & $4.77-11.28$ \\
\hline GU1001 & $4 / 8 / 2010$ & 20.0641 & -87.1886 & Neuston & 17 & $2.86-6.72$ \\
\hline GU1001 & $4 / 8 / 2010$ & 20.1165 & -87.0748 & S-10 & 2 & $9.39-11.95$ \\
\hline GU1001 & 4/8/2010 & 20.1693 & -86.9623 & S-10 & 5 & $3.55-4.4$ \\
\hline GU1001 & 4/9/2010 & 20.2411 & -86.8641 & S-10 & 1 & 4.12 \\
\hline GU1001 & 4/9/2010 & 20.5005 & -86.7161 & S-10 & 2 & 3.81 \\
\hline GU1001 & 4/9/2010 & 20.5023 & -85.8713 & S-10 & 2 & $3.88-6.67$ \\
\hline GU1001 & 4/9/2010 & 20.5105 & -85.4938 & S-10 & 2 & $3.64-3.89$ \\
\hline GU1001 & $5 / 12 / 2010$ & 26.0054 & -87.5019 & S-10 & 1 & 3.87 \\
\hline GU1001 & $5 / 12 / 2010$ & 26.0148 & -87.994 & S-10 & 2 & $2.08-2.87$ \\
\hline GU1001 & $5 / 12 / 2010$ & 26.2829 & -86.9944 & S-10 & 2 & $2.8-3.12$ \\
\hline GU1001 & $5 / 12 / 2010$ & 26.501 & -87.0005 & S-10 & 3 & $3.78-4.32$ \\
\hline GU1001 & $5 / 13 / 2010$ & 26.5063 & -87.9937 & S-10 & 1 & 2.96 \\
\hline GU1001 & $5 / 22 / 2010$ & 26.0029 & -88.9991 & S-10 & 1 & 4.11 \\
\hline GU1101 & $3 / 31 / 2011$ & 18.8942 & -78.2623 & S-10 & 1 & 6.5 \\
\hline GU1101 & $4 / 1 / 2011$ & 18.7633 & -74.9499 & S-10 & 1 & 3.9 \\
\hline GU1101 & $4 / 16 / 2011$ & 16.975 & -84.4886 & S-10 & 3 & $4.2-5.1$ \\
\hline GU1101 & $4 / 16 / 2011$ & 17.118 & -84.3708 & S-10 & 1 & 6.9 \\
\hline GU1101 & $4 / 17 / 2011$ & 16.9395 & -85.2278 & S-10 & 1 & 5.4 \\
\hline GU1101 & $4 / 19 / 2011$ & 16.83 & -87.0612 & S-10 & 1 & 4 \\
\hline GU1101 & $4 / 19 / 2011$ & 17.2533 & -86.4111 & S-10 & 1 & 6.46 \\
\hline
\end{tabular}




\begin{tabular}{|c|c|c|c|c|c|c|}
\hline Cruise & Date & Latitude & Longitude & Gear & $\mathbf{N}$ & Standard Length $(\mathrm{mm})$ \\
\hline GU1101 & $4 / 19 / 2011$ & 17.2533 & -86.4111 & Neuston & 1 & 6.29 \\
\hline GU1101 & $4 / 21 / 2011$ & 18.8438 & -86.8526 & S-10 & 2 & $5.6-8.9$ \\
\hline GU1101 & $4 / 21 / 2011$ & 18.8438 & -86.8526 & Neuston & 1 & 7.6 \\
\hline GU1101 & $4 / 23 / 2011$ & 20.0735 & -86.1522 & S-10 & 1 & 6.9 \\
\hline GU1101 & $4 / 23 / 2011$ & 20.2111 & -87.1356 & S-10 & 1 & 7.9 \\
\hline GU1101 & $4 / 24 / 2011$ & 21.0748 & -86.1676 & Neuston & 1 & 13 \\
\hline GU1101 & $4 / 25 / 2011$ & 20.4113 & -87.1545 & S-10 & 1 & 6.25 \\
\hline GU1101 & $4 / 25 / 2011$ & 20.4113 & -87.1545 & Neuston & 2 & $3.25-8$ \\
\hline GU1101 & $4 / 25 / 2011$ & 20.4343 & -87.0401 & S-10 & 1 & 17.5 \\
\hline GU1101 & $4 / 25 / 2011$ & 20.4933 & -87.0773 & S-10 & 3 & $6.7-11.87$ \\
\hline GU1101 & $4 / 3 / 2011$ & 17.7941 & -75.4387 & S-10 & 1 & 10 \\
\hline GU1101 & $4 / 3 / 2011$ & 18.1151 & -74.99 & S-10 & 1 & 9.5 \\
\hline GU1101 & $4 / 3 / 2011$ & 18.5355 & -74.9028 & Neuston & 1 & 10.7 \\
\hline GU1101 & $4 / 5 / 2011$ & 18.8322 & -78.0036 & S-10 & 1 & 4.8 \\
\hline GU1101 & $4 / 5 / 2011$ & 18.9693 & -77.7284 & Neuston & 1 & 3.4 \\
\hline GU1101 & $4 / 6 / 2011$ & 18.1357 & -79.8196 & Neuston & 1 & 6.2 \\
\hline GU1101 & $5 / 15 / 2011$ & 28.009 & -89.0103 & S-10 & 1 & 23.1 \\
\hline GU1101 & $5 / 22 / 2011$ & 26.5008 & -90.999 & S-10 & 1 & 8.37 \\
\hline GU1101 & $5 / 23 / 2011$ & 25.9993 & -89.3346 & S-10 & 1 & 3.79 \\
\hline GU1101 & $5 / 24 / 2011$ & 26.0165 & -88.9946 & S-10 & 1 & 3.84 \\
\hline GU1101 & $5 / 25 / 2011$ & 25.9875 & -87.498 & S-10 & 3 & $4.95-8.82$ \\
\hline GU1101 & $5 / 25 / 2011$ & 26.2705 & -87.0073 & S-10 & 12 & $3.25-6.99$ \\
\hline GU1101 & $5 / 25 / 2011$ & 26.489 & -86.9971 & S-10 & 3 & $6.76-11.86$ \\
\hline GU1101 & $5 / 25 / 2011$ & 26.489 & -86.9971 & Neuston & 1 & 5.32 \\
\hline GU1101 & $5 / 26 / 2011$ & 26.9955 & -86.992 & S-10 & 12 & $3.44-9.32$ \\
\hline GU1101 & $5 / 26 / 2011$ & 26.9955 & -86.992 & Neuston & 7 & $6.73-13.94$ \\
\hline GU1101 & $5 / 26 / 2011$ & 27.7516 & -87.0018 & S-10 & 1 & 9.42 \\
\hline GU1101 & $5 / 27 / 2011$ & 28.826 & -87.0031 & S-10 & 1 & 6.02 \\
\hline GU1101 & $5 / 3 / 2011$ & 23.9987 & -83.4882 & S-10 & 2 & $4.85-10.71$ \\
\hline GU1101 & $5 / 4 / 2011$ & 24.5111 & -83.986 & Neuston & 1 & 8.09 \\
\hline GU1101 & $5 / 5 / 2011$ & 24.9918 & -85.5051 & S-10 & 1 & 8.7 \\
\hline GU1101 & $5 / 5 / 2011$ & 24.9925 & -85.0026 & S-10 & 3 & $6.04-13.02$ \\
\hline GU1101 & $5 / 8 / 2011$ & 27.5095 & -86.994 & S-10 & 1 & 4.88 \\
\hline GU1201 & $4 / 30 / 2012$ & 24.986 & -85.5063 & S-10 & 8 & $4.37-9.8$ \\
\hline GU1201 & $4 / 30 / 2012$ & 24.9925 & -85.0145 & S-10 & 1 & 4.74 \\
\hline GU1201 & $5 / 1 / 2012$ & 24.0006 & -83.9836 & S-10 & 1 & 4.07 \\
\hline GU1201 & $5 / 1 / 2012$ & 24.5016 & -84.4856 & S-10 & 1 & 5.82 \\
\hline GU1201 & $5 / 17 / 2012$ & 26.9988 & -88.4993 & S-10 & 2 & $2.79-3.64$ \\
\hline GU1201 & $5 / 2 / 2012$ & 23.9906 & -83.4855 & S-10 & 1 & 6.09 \\
\hline GU1201 & $5 / 22 / 2012$ & 26.0206 & -95.0118 & S-10 & 1 & 4.87 \\
\hline GU1201 & $5 / 22 / 2012$ & 26.0206 & -95.0118 & Neuston & 1 & 4.19 \\
\hline GU1201 & $5 / 26 / 2012$ & 26.9991 & -88.4921 & S-10 & 1 & 4.76 \\
\hline
\end{tabular}


Cruise Date Latitude Longitude Gear

N Standard Length (mm)

GU1201

$5 / 26 / 2012 \quad 27.1701$

-88.254 S-10

GU1201 5/3/2012 25.9948

$-84.9971 \quad \mathrm{~S}-10$

3.62-3.93

GU1201

$5 / 3 / 2012 \quad 26.0026$

$-84.5 \quad \mathrm{~S}-10$

GU1201

$5 / 3 / 2012 \quad 26.4983$

$-84.9938 \quad \mathrm{~S}-10$

GU1201

$5 / 3 / 2012 \quad 26.4983$

-84.9938 Neuston

4.54-7.96

8.05

16.52

GU1201

$5 / 3 / 2012 \quad 27.0031$

$-84.9968 \quad \mathrm{~S}-10$

5.15

GU1201

$5 / 3 / 2012 \quad 27.0031$

-84.9968 Neuston

7.12-7.73

9.59

11.44

GU1201

$5 / 5 / 2012 \quad 27.506$

-86.005 Neuston

4.55

GU1201

$5 / 5 / 2012 \quad 28.5051$

$-86.0021 \quad \mathrm{~S}-10$

3.22-5.07

GU1201

$5 / 6 / 2012 \quad 24.9853$

$-86.0033 \quad \mathrm{~S}-10$

8.9

GU1201

$5 / 6 / 2012 \quad 26.0016$

-86.0033 Neuston

12.47

GU1201

$5 / 7 / 2012 \quad 26.0066$

-86.0136 Neuston

8.37

-87.4911 S-10

7.69

GU1201

$5 / 9 / 2012 \quad 27.4965$

-86.9958 S-10

5.03-6.79 